Original Research

\title{
Nowcasting Wind, Wave, Current and Turbulence Intensity for Offshore Wind Power Operation and Maintenance
}

\author{
Shih-Ang Hsu *
}

Coastal Studies Institute, Louisiana State University, Baton Rouge, LA 70803, USA; E-Mail: sahsu@Isu.edu

* Correspondence: Shih-Ang Hsu; E-Mail: sahsu@lsu.edu

Academic Editor: Aritra Ghosh

Special Issue:

Journal of Energy and Power Technology

2021, volume 3, issue 1

doi:10.21926/jept.2101014
Received: December 21, 2020

Accepted: March 21, 2021

Published: March 24, 2021

\begin{abstract}
In order to improve offshore wind power operation and maintenance (O\&M), particularly during tropical and non-tropical cyclones, short-term forecasts or nowcasts up to 6 hours of meteorological and oceanographic (met-ocean) parameters including wind, waves, currents and turbulence intensity are needed. On the basis of numerous air-sea and wind-wave interaction experiments, datasets are analyzed including those from simultaneous measurements of wind and waves during Hurricane Wilma. Formulas are presented for nowcasts of met-ocean parameters. For quality assurance, these proposed formulas are further verified by independent datasets as provided in the literature. This manual-like guide should be useful for offshore wind-power O\&M technicians and operators.
\end{abstract}

\section{Keywords}

Offshore wind power; wind-wave interaction; tropical and non-tropical cyclones; turbulence intensity; nowcast met-ocean parameters

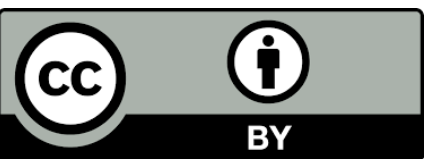

(C) 2021 by the author. This is an open access article distributed under the conditions of the Creative Commons by Attribution License, which permits unrestricted use, distribution, and reproduction in any medium or format, provided the original work is correctly cited. 


\section{Introduction}

According to the Glossary of the U. S. National Weather Service (https://w1.weather.gov/glossary/index.php?letter=n), nowcast is a short-term weather forecast, generally out to six hours or less. While global or regional weather forecasts are routinely available, e.g. from the European Centre for Medium-Range Weather Forecasts (ECWMF) or the U.S. National Center for Environmental Prediction (NCEP), it is the purpose of this study to supplement or valueadded nowcast for a smaller area within the forecasted domain such as an offshore wind farm. Using the wind or wave forecasts by the ECWMF or NCEP, we further add the nowcast for wind-driven current and overwater turbulence intensity, which are needed for offshore wind power operation and maintenance (O\&M).

According to [1-3], for aerodynamically rough flow over the ocean, approximately, the wind speed at $10 \mathrm{~m}$ (meters), $U_{10} \geq 9 \mathrm{~m} / \mathrm{s}$ and for a wind sea, the wave steepness, $H_{s} / L_{p} \geq 0.020$. Here $H_{s}$ is the significant wave height $(m), L_{p}\left(=1.56 T_{p}{ }^{2}\right)$ is the dominant wavelength $(m)$ and $T_{p}$ is the peak wave period (in seconds). Note that the wave parameter, $H_{s} / L_{p}$, is called wave steepness. Therefore, we define here that when $U_{10} \leq 9 \mathrm{~m} / \mathrm{s}$ and $H_{s} / L_{p} \leq 0.020$, fair weather and swell dominant conditions exist and they are not of major meteorological and oceanographic (met-ocean) concerns from the viewpoints of offshore wind power O\&M. In other words, when a wind farm is under gale or tropical cyclone conditions, nowcasts of wind, wave, current and turbulence intensity are more important. Following topics are our proposed manual-like guide for such an endeavor.

\section{Nowcasting Wind and Waves}

According to [3], during extra-tropical or tropical cyclone conditions, approximately,

$$
\mathrm{U}_{10}=\frac{35 \mathrm{H}_{\mathrm{s}}}{\mathrm{T}_{\mathrm{p}}}
$$

Here $T_{p}$ is the peak or dominant wave period (in seconds).

Further verification of Eq. (1) during a tropical cyclone is presented in Figure 1. Since the slope is unity and the correlation coefficient $R=0.85$, we can say that Eq. (1) is useful for operational use. In order to validate Eq. (1) under non-tropical cyclone conditions, Table 1 is provided and the result is shown in Figure 2. If one accepts the statistics given in Figure 3 and Figure 4, Eq. (1) is also applicable in Lake Ontario [4] and the Southern Ocean [5].

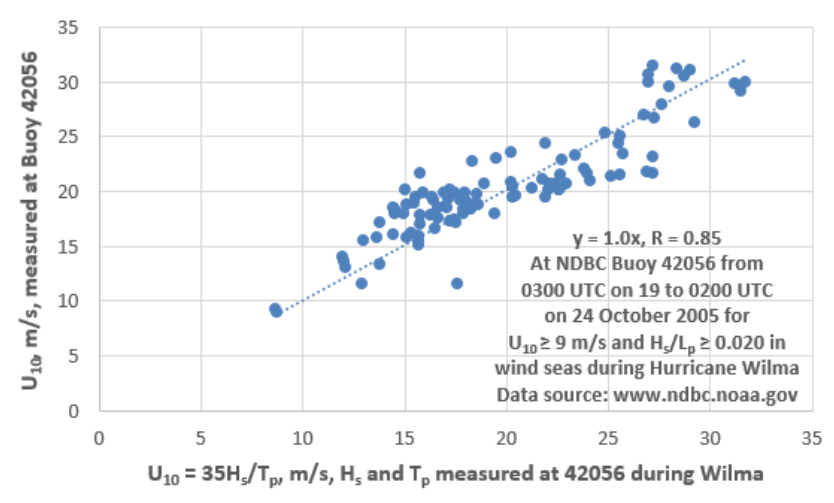

Figure 1 Verifying Eq. (1) at Buoy 42056 during Hurricane Wilma in 2005. 
Table 1 Datasets for the four non-tropical cyclones used in this study (Data source: www.ndbc.noaa.gov). Note that the wind speed measured at Buoys 45008 and 42360 were adjusted to $U_{10}$ according to the wind-gust method as presented in [3].

\begin{tabular}{lllll}
\hline Year & Month & Day & Buoy & Location \\
\hline 1993 & 3 & $12-14$ & 42003 & Gulf of Mexico \\
1996 & 11 & $2-5$ & 46035 & Bering Sea \\
2003 & 11 & $13-14$ & 45008 & Lake Huron \\
2018 & 12 & $26-27$ & 42360 & Gulf of Mexico \\
\hline
\end{tabular}

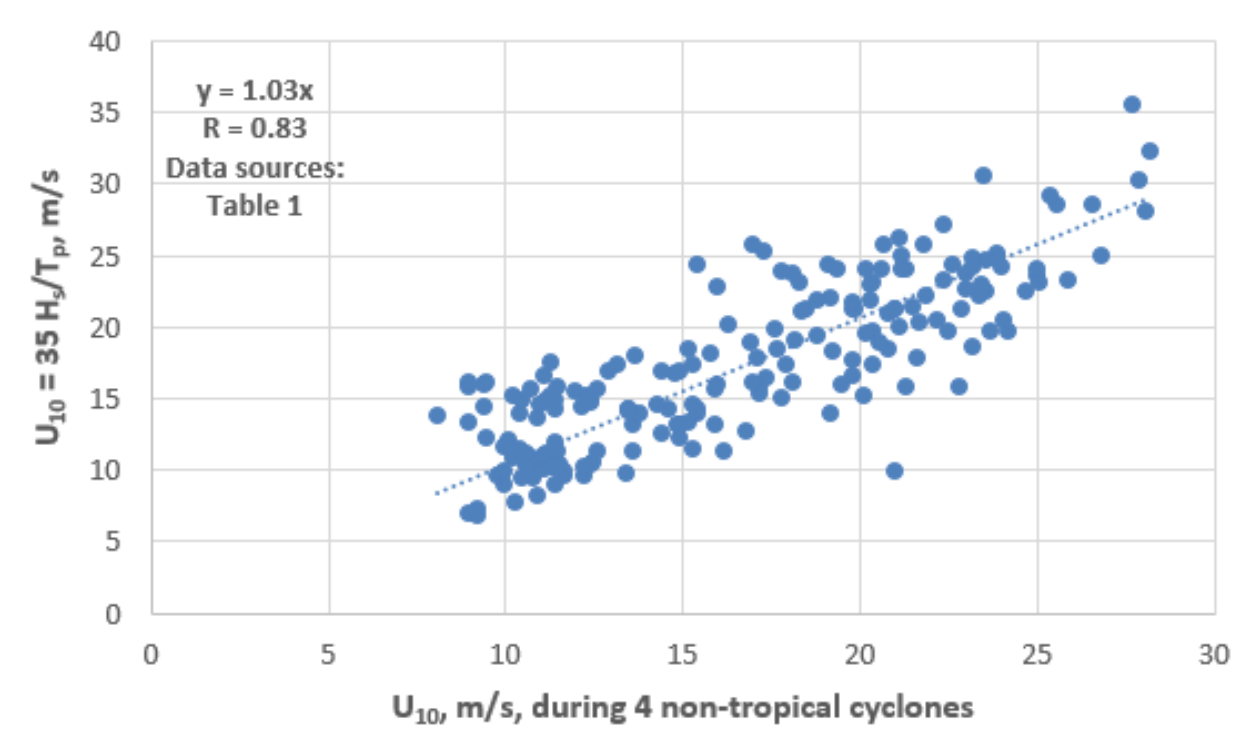

Figure 2 A verification of Eq. (1) under non-tropical cyclone conditions.

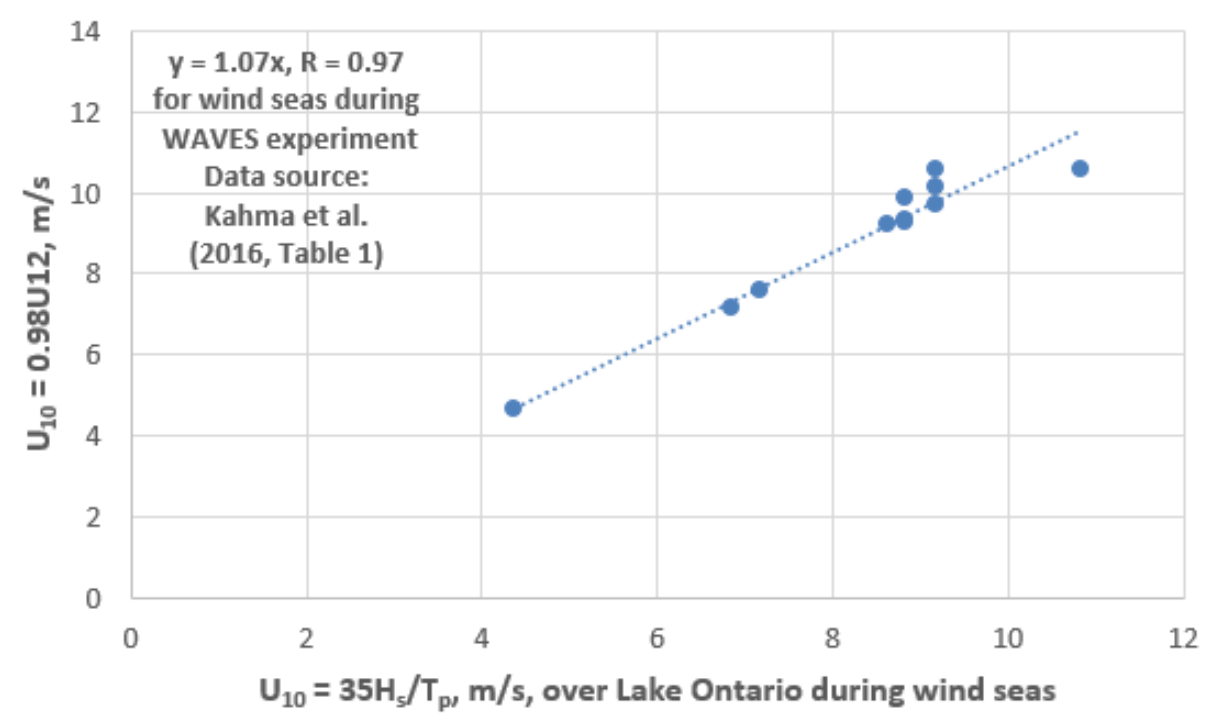

Figure 3 Validating Eq. (1) in Lake Ontario. 


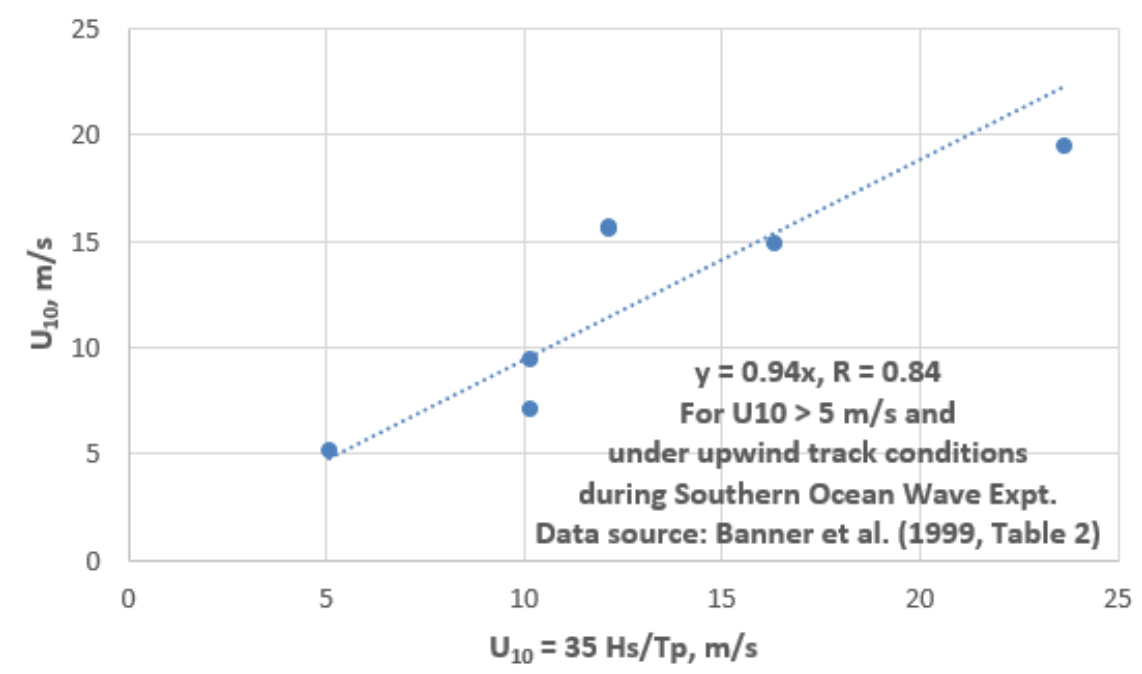

Figure 4 Validating Eq. (1) in the Southern Ocean.

Table 2 Examples of estimating winds and currents using the extreme wave measurements during Hurricane Ivan in 2004 based on Teague et al. [14].

\begin{tabular}{llllll}
\hline Parameter & M3 & M4 & M5 & M6 & Mean \\
\hline $\mathrm{H}_{\mathrm{s}}, \mathrm{m}$ measured & 18.0 & 16.1 & 17.7 & 14.8 & 16.7 \\
$\mathrm{U}_{10}, \mathrm{~m} / \mathrm{s}$ estimated & 47.5 & 43.1 & 46.8 & 40.1 & 44.4 \\
$\mathrm{U}_{\text {sea }}, \mathrm{m} / \mathrm{s}$ measured & 1.73 & 1.96 & 1.91 & 1.82 & 1.86 \\
$\mathrm{U}_{\text {sea, }} \mathrm{m} / \mathrm{s}$ estimated & 2.09 & 1.77 & 2.04 & 1.57 & 1.87 \\
\hline
\end{tabular}

If $T_{p}$ is not available, on the basis of Figure 5 during Hurricane Wilma near the National Data Buoy Center (NDBC) Buoy 42056 (see https://www.ndbc.noaa.gov/hurricanes/2005/wilma/), it may be estimated as

$$
\frac{\mathrm{H}_{\mathrm{s}}}{\mathrm{T}_{\mathrm{p}}}=0.0064 \mathrm{H}_{\mathrm{s}}+0.16
$$

With $\mathrm{R}=0.96$.

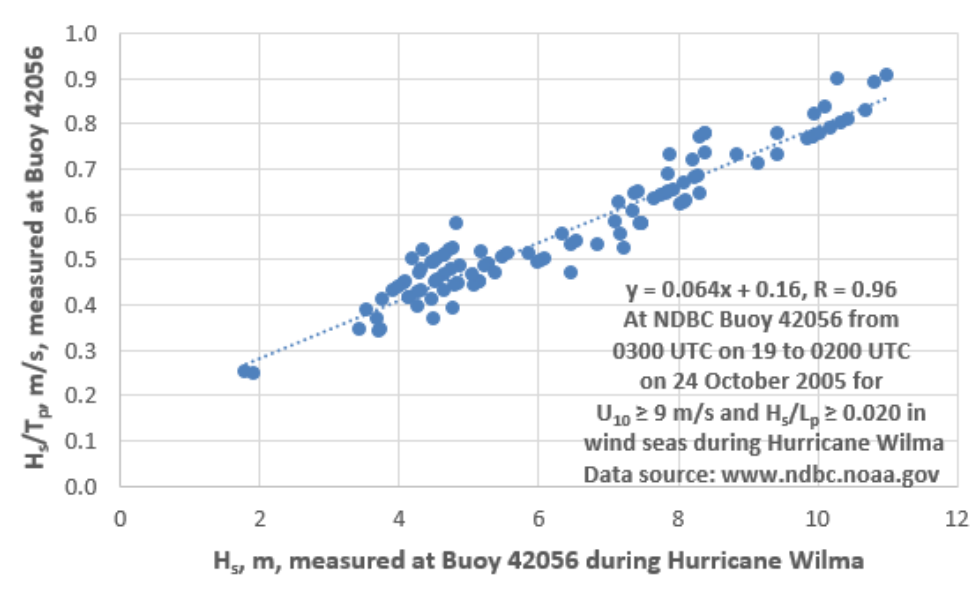

Figure 5 Relation between $\mathrm{H}_{\mathrm{s}} / \mathrm{T}_{\mathrm{p}}$ and $\mathrm{H}_{\mathrm{s}}$. 
So that $\mathrm{U}_{10}$ and $\mathrm{H}_{\mathrm{s}}$ are linearly related and according to Figure 6 , we have

$$
\mathrm{H}_{\mathrm{s}}=0.43 \mathrm{U}_{10}-2.4
$$

With $R=0.91$, Eq. (3) may be used to nowcast $H_{s}$ if $U_{10}$ is available and vice versa.

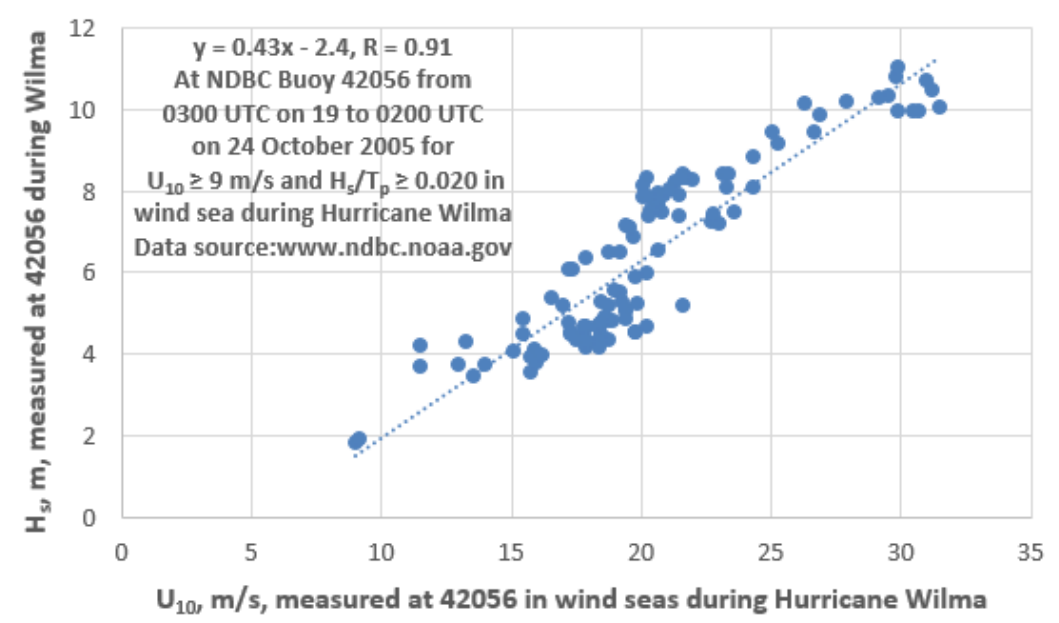

Figure 6 Relation between $\mathrm{H}_{\mathrm{s}}$ and $\mathrm{U}_{10}$.

\section{Nowcasting Overwater Turbulence Intensity}

Overwater turbulence intensity ( $\mathrm{TI})$ is an important parameter for offshore wind power $\mathrm{O}$ \& $\mathrm{M}$ [6]. According to [7-9], when the atmospheric stability is near neutral [10], we have

$$
\mathrm{TI}=\frac{2.5 \mathrm{U}_{*}}{\mathrm{U}_{10}}=\frac{1}{\operatorname{Ln}\left(\frac{10}{\mathrm{Z}_{\mathrm{o}}}\right)}
$$

And

$$
\frac{\mathrm{Z}_{\mathrm{o}}}{\mathrm{H}_{\mathrm{s}}}=1200\left(\frac{\mathrm{H}_{\mathrm{s}}}{\mathrm{L}_{\mathrm{p}}}\right)^{4.5}
$$

Here $U *$ is the friction velocity in $\mathrm{m} / \mathrm{s}$ and $\mathrm{Z}_{\mathrm{o}}$ is the aerodynamic roughness parameter in meters.

Simultaneous measurements of met-ocean parameters including $U_{10}, H_{s}$ and $T_{p}$ are available at Buoy 42056 during Hurricane Wilma. These data can be analyzed using Eqs. (4) and (5). Figure 7 and Figure 8 are the results for the relations between $\mathrm{TI}$ at $10-\mathrm{m}$ with $\mathrm{U}_{10}$ and $\mathrm{H}_{\mathrm{s}}$, respectively, so that

$$
\mathrm{TI}=0.0028 \mathrm{U}_{10}+0.0581
$$

With $\mathrm{R}=0.79$ and,

$$
\mathrm{TI}=0.006 \mathrm{H}_{\mathrm{s}}+0.0753
$$

With $R=0.83$. 


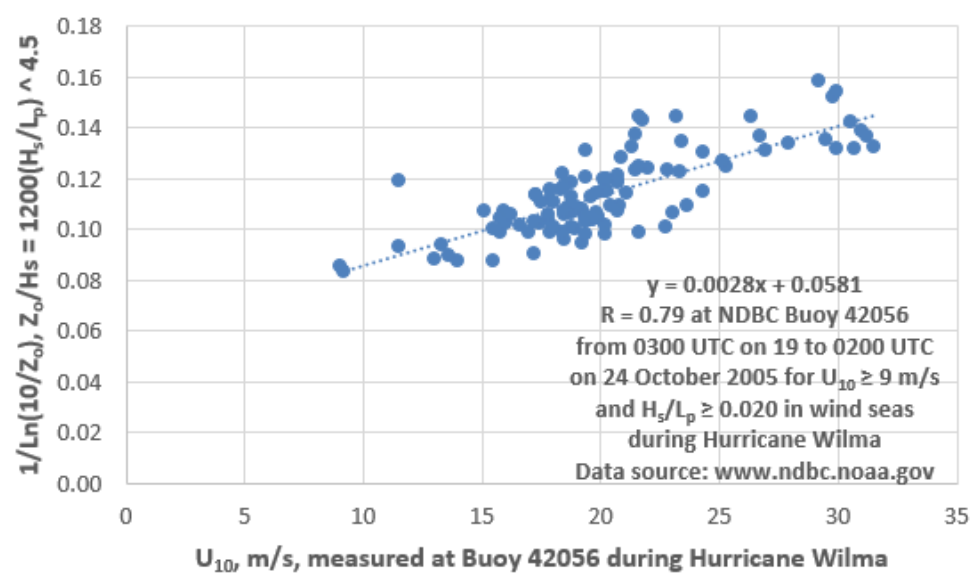

Figure 7 Variation of $\mathrm{Tl}$ at $10 \mathrm{~m}$ with $\mathrm{U}_{10}$.

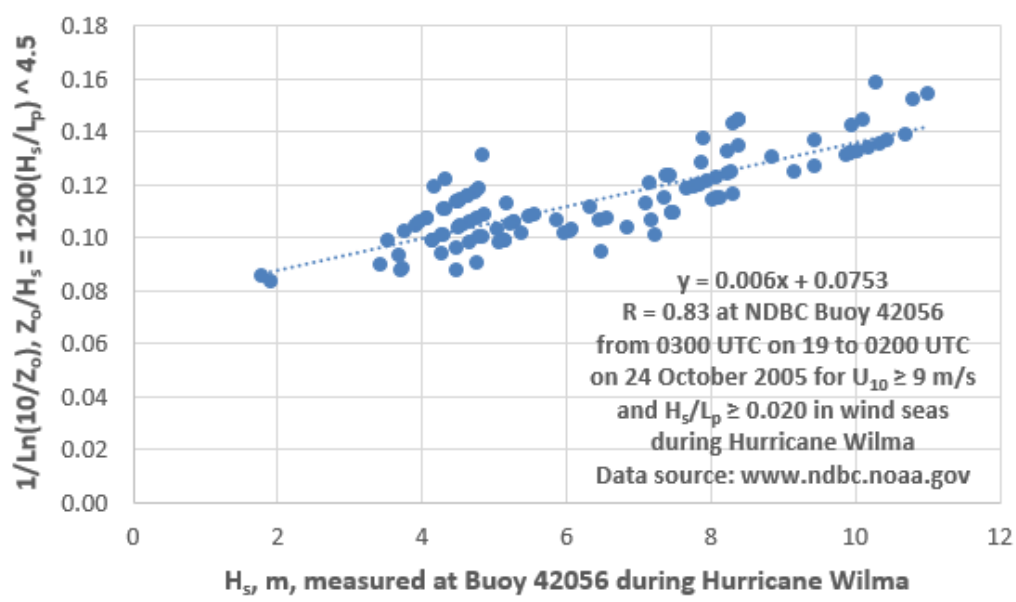

Figure 8 Variation of $\mathrm{Tl}$ at $10 \mathrm{~m}$ with $\mathrm{H}_{\mathrm{s}}$.

For quality assurance, Eq. (6) is compared with the TI formula by Smith [11]. It is a surprise that the result is nearly identical, indicating Eq. (6) is very useful for offshore wind power $O$ \& $M$, since it extends from gale force wind to hurricane condition.

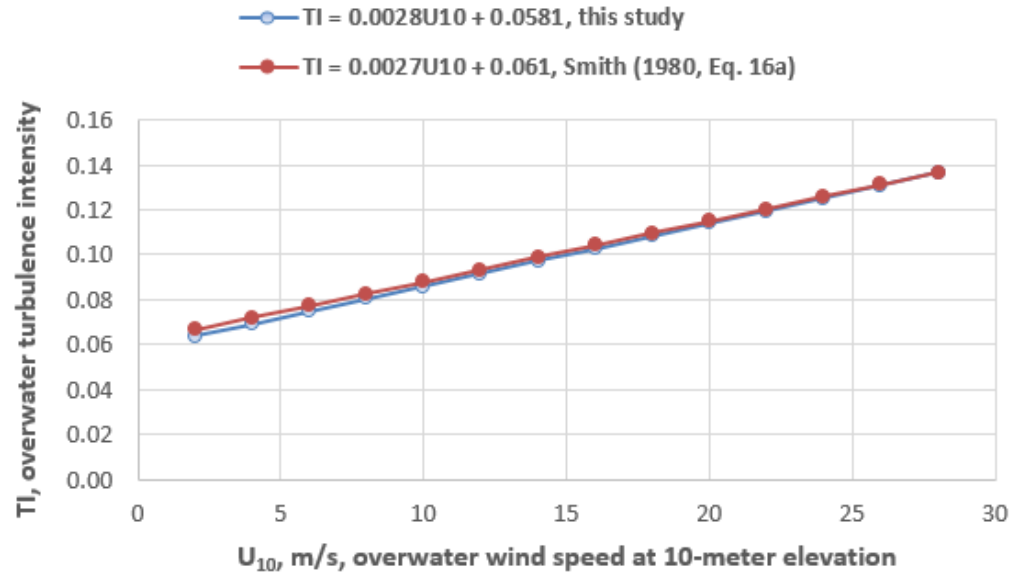

Figure 9 Comparison of Variation of $\mathrm{TI}$ at $10 \mathrm{~m}$ between Eq. (6) and the TI formula by Smith [11]. 


\section{Nowcasting Wind-Driven Currents}

Wind-driven currents are integral parts of total currents which also include those generated by the astronomical tides. For wind-driven currents, $U_{\text {sea, }}$ in $\mathrm{m} / \mathrm{s}$, according to [12] Eq. 4,

$$
\mathrm{U}_{\text {sea }}=0.57 \mathrm{U}_{*}
$$

From Eqs. (4) and (6), we have

$$
\mathrm{U}_{*}=0.4 \mathrm{U}_{10}\left(0.0028 \mathrm{U}_{10}+0.0581\right)
$$

On the basis of the datasets provided in [11] and [13], a verification of Eq. (9) is presented in Figure 10. Since the slope is unity and $R=0.97$, Eq. (9) is recommended for operational use.

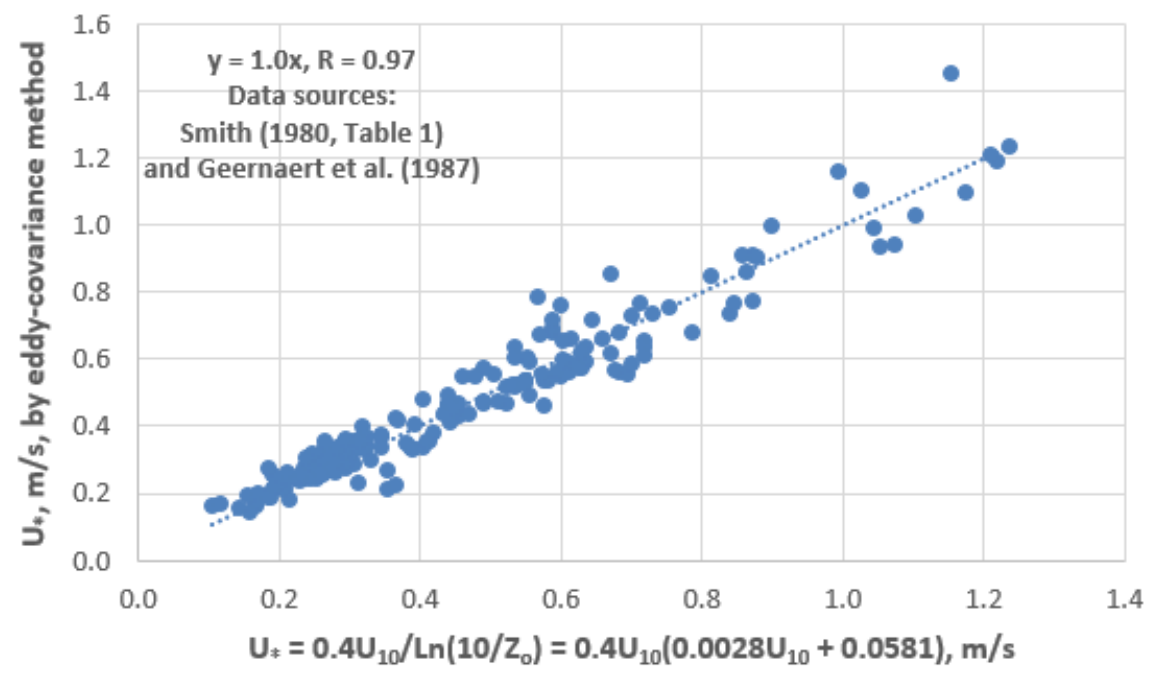

Figure 10 A verification of Eq. (9).

Now, by substituting Eq. (9) into Eq. (8), one gets

$$
\mathrm{U}_{\text {sea }}=0.23 \mathrm{U}_{10}\left(0.0028 \mathrm{U}_{10}+0.0581\right)
$$

Using Eq. (3) to convert $\mathrm{H}_{\mathrm{s}}$ to $\mathrm{U}_{10}$ for the datasets presented in [14] during Hurricane Ivan, Eq. (10) is validated in Table 2. Since the mean near-surface current is almost identical (in red) between the estimated and the measured, Eq. (10) is recommended for use in nowcasting.

\section{Conclusions}

On the basis of aforementioned analyses and discussions, it is concluded that

(1) Wind or waves can be nowcasted using Eq. (3) if either the wind or wave forecast is available;

(2) Overwater turbulence intensity at 10-m elevation can be nowcasted using Eq. (6) if the wind speed at 10-m is available or Eq. (7) if the significant wave height is available;

(3) Overwater friction velocity can be nowcasted using Eq. (9); and

(4) Wind-driven currents can be nowcasted using Eq. (10). 


\section{Author Contributions}

Shih-Ang Hsu did all work.

\section{Competing Interests}

The author has declared that no competing interests exist.

\section{References}

1. Andreas EL, Mahrt L, Vickers D. A new drag relation for aerodynamically rough flow over the ocean. J Atmos Sci. 2012; 69: 2520-2537.

2. Drennan WM, Taylor PK, Yelland MJ. Parameterizing the sea surface roughness. J Phys Oceanogr. 2005; 35: 835-848.

3. Hsu SA, He Y, Shen H. Buoy measurements of wind-wave relations during Hurricane Matthew in 2016. J Phys Oceanogr. 2017; 47: 2603-2609.

4. Kahma KK, Donelan MA, Drennan WM, Terray EA. Evidence of energy and momentum flux from swell to wind. J Phys Oceanogr. 2016; 46: 2143-2156.

5. Banner ML, Chen W, Walsh EJ, Jensen JB, Lee S, Fandry C. The Southern Ocean waves experiment. Part I: Overview and mean results. J Phys Oceanogr. 1999; 29: 2130-2145.

6. Argyle $\mathrm{P}$, Watson $\mathrm{S}$, Montavon $\mathrm{C}$, Jones I, Smith M. Modelling turbulence intensity within a large offshore wind farm. Wind Energy. 2018; 21: 1329-1343.

7. Hsu SA, Blanchard BW. Estimating overwater turbulence intensity from routine gust-factor measurements. J Appl Meteorol. 2004; 43: 1911-1916.

8. Hsu SA. Estimating overwater friction velocity and exponent of power-law wind profile from gust factor during storms. J Waterw Port Coast Ocean Eng. 2003; 129: 174-177.

9. Taylor PK, Yelland MJ. The dependence of sea surface roughness on the height and steepness of the waves. J Phys Oceanogr. 2001; 31: 572-590.

10. Hsu SA. An overwater stability criterion for the offshore and coastal dispersion model. Boundary Layer Meteorol. 1992; 60: 397-402.

11. Smith SD. Wind stress and heat flux over the ocean in gale force winds. J Phys Oceanogr. 1980; 10: 709-726.

12. Wu J. Sea-surface drift currents induced by wind and waves. J Phys Oceanogr. 1983; 13: 14411451.

13. Geernaert GL, Larsen SE, Hansen F. Measurements of the wind stress, heat flux, and turbulence intensity during storm conditions over the North Sea. J Geophys Res Oceans. 1987; 92: 1312713139.

14. Teague WJ, Jarosz E, Wang DW, Mitchell DA. Observed oceanic response over the upper continental slope and outer shelf during Hurricane Ivan. J Phys Oceanogr. 2007; 37: 2181-2206. 
JEPT 2021; 3(1), doi:10.21926/jept.2101014

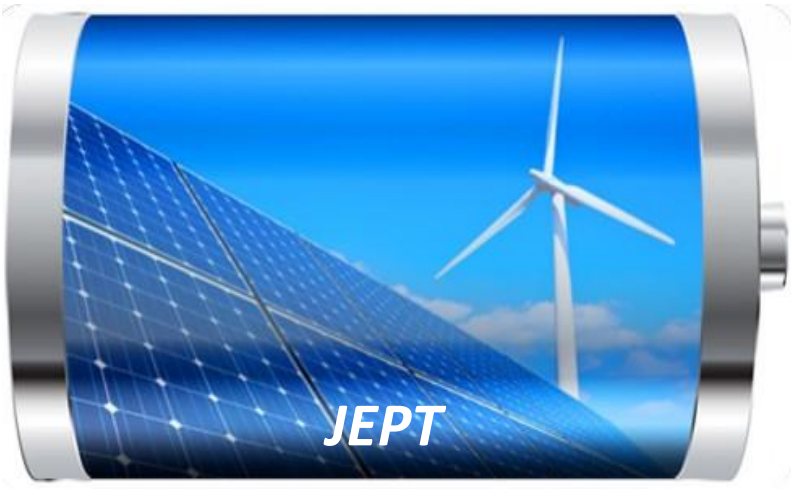

Enjoy JEPT by:

1. Submitting a manuscript

2. Joining in volunteer reviewer bank

3. Joining Editorial Board

4. Guest editing a special issue

For more details, please visit:

http://www.lidsen.com/journal/jept 